\title{
Editorial for EAIT issue 1, 2019
}

\author{
Arthur Tatnall ${ }^{1}$
}

Published online: 2 January 2019

(C) Springer Science+Business Media, LLC, part of Springer Nature 2018

The popularity of the journal of Education and Information Technologies continues to grow, with over four hundred and fifty papers received in 2018. Of these, about $40 \%$ were accepted for publication. As a result of this, the first issue of EAIT for 2019 is again a bumper issue with forty five papers. Again the papers show how international our researchers are and this issue of EAIT has articles from researchers in twenty nine countries: UK, Sri Lanka, Australia, Malaysia, Serbia, Spain, United Arab Emirates, South Africa, Iran, Thailand, USA, Ghana, Nigeria, Turkey, Kazakhstan, Greece, Tanzania, Israel, India, Canada, Fiji, Cyprus, Oman, Ukraine, Poland, Tunisia, Russia, Germany and Saudi Arabia.

The first article in this issue: "A study into the usability and security implications of text and image based challenge questions in the context of online examination" by Abrar Ullah (Cardiff Metropolitan University, UK) and Hannan Xiao and Trevor Barker (University of Hertfordshire, UK) looks at online examinations and academic dishonesty. Online examinations are seen as an integral component of online learning environments, and research studies have identified academic dishonesty as a critical threat to their credibility. Academic dishonesty exists in many forms, but collusion is seen as a major security threat. The reported research investigated the authentication of students using text-based and image-based challenge questions. They found that imagebased questions are more usable than text-based questions and the paper discusses ways to enhance this advantage.

The article that follows is by H. K. Salinda Premadasa, R. M. Kapila Tharanga Rathnayaka, A. Waruni Thiranagama and Chaminda Niroshan Walpita (Sabaragamuwa University of Sri Lanka). "Remodelling the educational usage of Facebook in smartmobile age" notes the popularity of Facebook as a social networking site and how this is being seen as a possible tool for education both inside and outside the classroom. Their research aim was to extend the existing structural model by two factors: mobility and interactivity, and they found that in the extended model, educational usage of Facebook was significantly related to its purpose and less significantly to its adoption.

Arthur Tatnall

Arthur.Tatnall@vu.edu.au

$1 \quad$ Victoria University, Australia, Melbourne, Australia 
"Influences on purposeful implementation of ICT into the classroom: An exploratory study of K-12 teachers" by Royce L. Willis, David Lynch, Paul Fradale and Tony Yeigh (Southern Cross University, Australia) notes that teachers are increasingly required to incorporate ICT into the classroom. This should not be seen as merely an add-on but should be based on pedagogy. Their study explored potential factors that might predict purposeful implementation of ICT into the classroom. They found a relationship between teachers having ICT skills that can personalize, engage and create an interactive atmosphere for students and purposeful implementation of ICT into the classroom.

The next article: "Decision to adopt online collaborative learning tools in higher education: A case of top Malaysian universities" from Elaheh Yadegaridehkordi and Liyana Shuib (University of Malaya, Malaysia), Mehrbakhsh Nilashi (Universiti Teknologi Malaysia) and Shahla Asadi (Universiti Putra Malaysia) notes that although cloud computing in now well-known, its adoption in an educational context has not reached its full potential. Few studies have considered student behaviour to adoption of cloud technology for online collaborative learning purposes, so their research sought to develop an adoption model for online collaborative learning tools in a cloud environment using the Technology Acceptance Model (TAM). They extend TAM by adding mobility, collaboration and personalization as external variables.

Following, Slaviša Radović and Miroslav Marić (from the University of Belgrade, Serbia and Don Passey (Lancaster University, UK) report how an ICT system can support greater connection across and outcomes from home and school mathematics learning practices for pupils of 11 to 14 years. "Technology enhancing mathematics learning behaviours: Shifting learning goals from 'producing the right answer' to 'understanding how to address current and future mathematical challenges"' details the purpose, background and theoretical basis of the study along with the design and methodological approach and the effects and contributions web-based home and school linked practice has on pupils and teachers. Findings highlighted the efficacy of the system, indicating benefits arising when pupils and teachers used the entire range of features.

We live in a society where Technology has an important position in our activities say Gonzalo Lorenzo, Asunción Lledó, Graciela Arráez-Vera and Alejandro LorenzoLledó (University of Alicante, Spain) in their article titled: "The application of immersive virtual reality for students with ASD: A review between 1990-2017". Their article looks at the use of Virtual Reality technology in the education of students with Autism Spectrum Disorder by providing a review of what studies have applied Immersive Virtual Reality to students with Autism Spectrum Disorder. These students can use Virtual Reality as a support to practice social situation that can be generalised in real environments. Their research considered the following variables: participants' features, research questions, instrument, type of activities, results and limitations.

In a paper titled: "Significance and challenges of computer assisted education programs in the UAE: A case study of higher learning and vocational education", Brinitha Raj (National Institute for Vocational Education, UAE) describes how due to the ever increasing demands for highly skilled workforce in the United Arab Emirates the government has focused on promoting vocational education for inculcating technical and professional skills in the young Emiratis. The uptake of technical vocational education and training (TVET) is relatively low in UAE, and to address this and 
promote TVET in the UAE the government has made efforts to introduce computer assisted education programs. The aim of this paper is to discuss whether or not computer aided learning programs help the students in vocational learning and to highlight the shortcomings of these systems in achieving the intended purpose.

"The use of activity theory to guide information systems research" comes from Tiko Iyamu and Irja Shaanika (Cape Peninsula University of Technology, South Africa). They note that Activity Theory (AT) is increasingly employed as a lens to guide data analysis in information systems studies and to assess and evaluate information systems and technologies in organisations. Even though its popularity continues to increase in both business and academic domains, there is no formal assessment guide through which the theory can be applied. Their study was undertaken to examine how the use of AT in IS studies could be made easy, and a three phase approach was developed and proposed to guide: the selection of AT in an IS/IT study, use of elements for data analysis and how the elements can be linked with AT components in the analysis of qualitative data.

Gonzalo Lorenzo, Marcos Gómez-Puerta, Graciela Arráez-Vera and Alejandro Lorenzo-Lledó (from the University of Alicante, Spain) then present: "Preliminary study of augmented reality as an instrument for improvement of social skills in children with autism spectrum disorder". They describe how many studies have shown that children with Autism Spectrum Disorders display a lack of social and communication skills, but that they understand, assimilate and retain better information using virtual aids. The objective of their study was to assess the effectiveness of an augmented reality training program based on visual support for students with Autism Spectrum Disorder in order to improve their social skills. Their investigation was carried out using an experimental group and a control group. The experimental group worked with augmented reality activities including a player who had to score a goal, and playing with a cow. The control group received similar interventions, such as picking up the objects according to the therapist's orders, but without the use of this tool. The results of the experiment did not show statistically significant differences between the groups, although slight improvements appear in some items.

The next article looks at connection and communication via social networking applications which the authors point out are one of the most important features in college students' lives. "Can effective study approaches mediate the negative effect of social networking on academic performance?" was contributed by Mohamamd Ali Rostaminezhad, Hadi Porshafeim and Ahmad Ali Ahamdi (University of Birjand, Iran). They argue that text and graphical messaging, and the generation, sharing and viewing of visual messages may affect students' academic life and especially their academic performance. Reports about the effect of social networking on academic performance have been inconsistent, and the reported study investigates the role of social networking on the academic performance of students regarding the mediating role of study approaches. Their findings suggest that social networking negatively affects academic performance.

The next article concerns the building of a Web-based knowledge structures system. Athitaya Nitchot and Wiphada Wettayaprasit (Prince of Songkla University, Thailand) and Lester Gilbert (University of Southampton, UK) offer: "Assistive tool for constructing knowledge structures and suggesting related study materials links". They point out that within Web-based learning it is difficult for learners to identify and choose study 
materials that match their current and desired abilities, and that learners may fail to recognize missing prerequisite learning, and fail to identify knowledge they seek. Most e-learning systems do not provide information to assist learners to avoid these difficulties. The authors propose pedagogically-informed knowledge structures and associated applications, including a tool for designing and building these structures, a tool for navigating the structures for particular purposes and a tool for recommending appropriate materials.

"Survey results on adults and cybersecurity education" by Joseph Ricci, Frank Breitinger and Ibrahim Baggili (University of New Haven, USA) remarks that cyberattacks and identity theft are common problems nowadays where researchers often say that humans are the weakest link the security chain. Their article presents a survey focused on analysing the interest for adults for 'cyber threat education seminars' and how to protect themselves. The results show that many are worried about cyber threats and about their children exploring the online domain, but that spending 1 to $1.5 \mathrm{~h}$ on seminars did not seem to be a priority.

Another article looking at activity theory comes from Ibrahim Osman Adam (University for Development Studies, Ghana), John Effah and Richard Boateng (University of Ghana Business School). "Activity theory analysis of the virtualisation of teaching and teaching environment in a developing country university" looks at understanding how a higher education institution in a developing country attempted to digitalise teaching. The Internet has disrupted the traditional teaching environment and teaching practices and this has led to the migration from face to face to online teaching, so changing a teacher's work environment. IS literature has examined the student perspective in a virtual learning environment, but not from that of an instructor in a teaching/work environment. Using activity theory and an interpretive case study approach, data was obtained from interviews, documents and participant observation for this research project.

In the article that follows: "The determinants of library and information science undergraduate students' first impression of university library websites" is by Adeyinka Tella (University of South Africa and University of Ilorin, Nigeria). The results demonstrate that there is significant correlation between library and information science students' Perception of Website Quality, Website Interactivity, Website Aesthetic Perception, Website Proto-Typicality and Website Satisfaction with first impression toward the university library website. Aesthetic perception of library website contributed most to the prediction of these students' first impression towards library websites, followed in declining order of strength by library website interactivity, library website satisfaction and library website quality.

"Development of eye movement games for students with low vision: Single-subject design research" presents a study about design and development of eye tracker-based eye training games to help students with low vision to improve their vision capabilities. The researchers were Mehmet Donmez and Kursat Cagiltay (from Middle East Technical University, Turkey). This study consists of an interative and incremental development process of the eye movement games and single subject design research by using the final product with a participant.

Next, Nuri Balta (University of International Business, Kazakhstan) and Katerina Tzafilkou (University of Macedonica, Greece) relate: “Using Socrative software for instant formative feedback in physics courses" aimed at understanding how students' attitudes were connected to the web based software Socrative. Their survey showed that 
there was no difference between attitudes of male and female students but that students in the civil engineering major had significantly more positive attitudes than molecular biology and genetic major students. This suggests that Socrative serves an important role in student engagement and attitudes toward physics.

The next article describes a study to understand how students use online forums and Twitter in undergraduate learning. "Understanding student use of twitter and online forums in higher education" comes from Eleanor J. Dommett (King's College London, UK). A survey was designed to assess students' general approach to these tools, the types of interaction experienced and specific uses. The study demonstrated that more students use forums than Twitter but that both tools provide support for learning outcomes aimed at increasing knowledge and understanding and key skills, but that they do this differently: Twitter provides access to news media and those outside their programme whilst forums support discussion with peers.

John Fungulupembe Kalolo (Mkwawa University College of Education, Tanzania) then offers: "Digital revolution and its impact on education systems in developing countries". Although the digital era has transformed most education processes and systems, a challenge has been how most developing countries including Tanzania can benefit from the digital era in education systems while avoiding its downsides. While understanding the infrastructural and resource challenges in the region, the paper seeks to address the knowledge gap related to the digital technology in education by pointing out both the problematic areas and the promising approaches to be adapted in the efforts to harness advantages of digital technology in education processes.

The integration of Quick Response (QR) codes in classrooms has been identified as an important tool in promoting active as well as distributed learning, especially in higher education say Siti Nazleen Abdul Rabu and Haniza Hussin (Universiti Sains Malaysia) and Brandford Bervell (Universiti Sains Malaysia and University of Cape Coast, Ghana) in: " $Q R$ code utilization in a large classroom: Higher education students' initial perceptions". They note that even though the versatility of this technology within the educational milieu cannot be over-emphasized, the initial perceptions of students who are at the centre of QR integration are important towards achieving the prospects of this technology in the pedagogical process, particularly in a large classroom context. Against this backdrop, the Technology Acceptance Model (TAM) and Unified Theory of Acceptance and Use of Technology2 (UTAUT2) were employed as a theoretical foundation to study students' perceptions. Initial results suggested that students had very positive attitudes towards QR code utilization for course related activities which ultimately determined their intentions to accept this technology.

“Teachers' perceptions of out-of-class communication, teacher-student relationship, and classroom environment" describes research by Amir Abd Elhay and Arnon Hershkovitz (Tel Aviv University, Israel) who reflect that communication between students and teachers is usually extended beyond the classroom's time and space and that this out-of-class communication may impact students' academic, social, and emotional development. This is facilitated via social media and instant messaging services which may affect its nature, and their study analysed the impact of WhatsApp communication between middle and high-school teachers and their students on the teacher-student relationship and the classroom environment.

Anju Kamal and Souhreda Radhakrishnan (Amritapuri and Amrita Vishwa Vidyapeetham, India) then offer: "Individual learning preferences based on 
personality traits in an E-learning scenario". They note that differences in learning styles are an important consideration at all levels of education. Examining college students' preferred style of learning is useful for course design and effective instructional methods. Their research investigated the relationship between personality traits and learning styles among millennial students in an e-learning scenario, and concluded that effectiveness of e-learning courses can be improved by providing instruction in a manner consistent with each student's learning style and personality traits.

The article that follows: "Advising the whole student: eAdvising analytics and the contextual suppression of advisor values" is by Kyle M. L. Jones (Indiana UniversityIndianapolis, USA) who remarks that institutions are applying methods and practices from data analytics under the umbrella term of 'learning analytics' to inform instruction, library practices, and institutional research. This study reports findings from interviews with professional advisors at a public higher education institution and examines their perspective on their institution's recent adoption of eAdvising technologies with prescriptive and predictive advising affordances. Findings detail why advisors rejected the tools due to usability concerns, moral discomfort and a belief that using predictive measures violated a professional ethical principle to develop a comprehensive understanding of their advisees.

David John Lemay (McGill University, Canada), Ram B. Basnet (Colorado Mesa University, USA), Tenzin Doleck and Paul Bazelais (McGill University, Canada) next present: "Social network analysis of twitter use during the AERA 2017 annual conference". Their study relates to use of Twitter during the American Educational Research Association 2017 Annual Conference. It considers social network analysis and provides insight into the educational research community as it manifests and evolves online. The overall social network is sparse with low density, with a few very active nodes and many unconnected Twitter users. Tweets were positive or neutral and rarely negative. Degree of centrality and closeness of the top ten users is high relative to the top 100 users as centrality, closeness, and betweenness taper off quickly.

Mobile learning adoption is an active area of research and Bimal Aklesh Kumar and Sailesh Saras Chand (Fiji National University) discuss this in: "Mobile learning adoption: A systematic review". Their paper aims to contribute to better understanding of mobile learning adoption by providing a body of knowledge to aid researchers working in this field. Results highlighted publication trend, adoption models used and a set of factors that influence mobile learning adoption.

"Perceived impact of BYOD initiatives on post-secondary students' learning, behaviour and wellbeing: the perspective of educators in Greece" describes research by Christos Livas and Ioannis Katsanakis (University of Piraeus, Greece) and Eleni Vayia (Open University of Cyprus). An alternative strategy of technology integration, 'Bring Your Own Device' involves the introduction of personal digital devices in numerous educational activities and transforms students' learning experiences, behavioural responses and aspects of wellbeing. This study investigated the potential effects of this on students' learning, behaviour and wellbeing.

"Factors affecting the E-learning acceptance: A case study from UAE" comes from Said A. Salloum (The British University in Dubai and University of Fujairah, UAE), Mostafa Al-Emran (Universiti Malaysia Pahang and Sultan Qaboos University, Oman), Khaled Shaalan (The British University in Dubai, UAE) and Ali Tarhini (Sultan Qaboos University, Oman). The authors have proposed a new model that aims 
to investigate the impact of innovativeness, quality, trust, and knowledge sharing on Elearning acceptance. The outcomes revealed that university knowledge sharing and quality have a positive influence on E-learning acceptance among the students, but that innovativeness and trust did not significantly affect this.

The article following: "A governance operating model for open and distance learning institutions" by Pankaj Khanna (Indira Gandhi National Open University, India) describes an effective governance operating model that would encourage achievement of enhanced good governance during the overall working of open and distance learning institutions. This model is proposed in three layers of network: the organisational design and governance system, governance operating systems and IT infrastructure. This governance operating model should enhance the efficiency, effectiveness and overall performance of the open and distance learning institution involved.

Manuel Area Moreira, Víctor Manuel Hernández Rivero and Juan José Sosa Alonso (University of La Laguna, Tenerife, Spain) next offer: "Leadership and school integration of ICT: Teachers perceptions in Spain". Studies have shown that educational leadership is a relevant factor in the process of instructional integration of digital technologies in classrooms and their article analyses the perceptions that teachers have about leadership of the ICT coordinator, an educational agent whose main mission is to promote the process of pedagogical integration of technologies in the school. It is argued that the coordinator must have ICT skills of various kinds that are more complex than mere instrumental mastery of technology and are linked to support the innovative use of ICT in teaching and learning by the teaching staff of a school.

What comes next is: "Technological aspect factors of E-learning readiness in higher education institutions: Delphi technique" by Asma Ali Mosa Al-araibi, Mohd Naz'ri bin Mahrin and Rasimah Che Mohd Yusoff (Universiti Teknologi Malaysia). They begin by reflecting that E-learning is an educational method which aims to provide educational or training programs for students or trainees at any time and at any place using ICT, and that increasing numbers of higher education institutions have adopted this to take advantage of the opportunities it offers. Through e-learning, learners can access resources and information from anywhere and at any time, but the successful implementation of e-learning relies on readiness of an institution is to adopt and implement it.

"An investigation of motivation and experience in virtual learning environments: a self-determination theory" follows. It was written by Yu-Chih Huang (National Chi Nan University, Taiwan), Sheila J. Backman, Kenneth F. Backman, Francis A. McGuire and DeWayne Moore (Clemson University, USA) and points out that with the development and evaluation of information technology, virtual reality technology provides opportunities to offer an immersive and interactive experience for supplementing traditional classroom lectures and creating innovative online learning in education curricula and professional training. Given that the arena of 3D entertainment-oriented virtual worlds is creative and quickly evolving, applying a theory-based motivational model to examine the properties of virtual world environments in the context of education remains relatively unexplored territory and this study applies the research frameworks of Self-Determination Theory and hedonic theory to an understanding of this.

Next, Sucheta V. Kolekar, Radhika M. Pai and Manohara Pai M. M. (Manipal Institute of Technology, India) present: "Rule based adaptive user interface for 
adaptive E-learning system". This term refers to the set of techniques and approaches that are combined together to offer online courses to the learners with the aim of providing customised resources and interfaces and most of these systems focus on adaptive contents which are generated for the learners without considering their learning styles. This paper proposes a generic approach to provide the learning contents with Adaptive User Interface components based on the learning styles of the learners.

In technology acceptance studies, both the theory of reasoned action (TRA) and the technology acceptance model (TAM) have been widely adopted to study the factors that influence users' technology usage intentions. Charles Buabeng-Andoh and Winfred Yaokumah (Pentecost University College, Ghana) and Ali Tarhini (Sultan Qaboos University, Oman) compare these in: “Investigating students' intentions to use ICT: A comparison of theoretical models". They observe that although these frameworks have been tested in Western nations, there has been little effort to apply them elsewhere, and with the globalisation of education and technology there is a need to know whether TRA and TAM apply in other cultures. This study compared TRA, TAM and integrated frameworks that best explained or predicted students' technology usage intention, but found that there were no differences in predictive strength of behavioural intention between these models.

"Online assessments: Exploring perspectives of university students" by Sarah Khan (Zayed University, UAE) and Rashid Azim Khan (Etisalat Digital, UAE). The United Arab Emirates is committed to integrating technology into higher education, say the researchers. The paper explores the perspectives of university students on online assessments, as an understanding of students' views can help identify obstacles and promotors in embracing online assessments at the undergraduate level. The study highlighted that students did not comprehend the need for online assessments and felt they were restrictive for their science courses and had resulted in falling grades, probably due to the increasing dependence on multiple choice questions.

The next article was contributed by: Maryna Diachenko-Bohun (Poltava V. G. Korolenko National Pedagogical University, Ukraine), Nataliia Hrytsai (Rivne State University of Humanities, Ukraine), Maryna Grynova (Poltava V. G. Korolenko National Pedagogical University, Ukraine), Igor Grygus (National University of Water and Environmental Engineering, Ukraine) and Walery Zukow (Nicolaus Copernicus University, Poland). In "The readiness formation of future biology teachers for healthcare-safety technologies realization in professional activity" they claim that the deterioration of the quality of life, mental, physical, and social human disorders reveal themselves in reducing the level of adaptation to daily psychological and physical stress, early development of neuroses, psychosomatic and mental illness in children and adults. One strategy for development of educational institutions is the organisation of healthcare activities and so the task of forming the readiness of future biology teachers to implement healthcare-saving technologies in the professional activity is of significant importance. The article describes results of a pedagogical experiment conducted among future biology teachers within the the natural sciences faculties of pedagogical higher educational institutions.

Researching the use of technology to assist in the education for students with disabilities is of great importance and "The role of DAISY digital talking books in the education of individuals with blindness: A pilot study" by Vassilios Argyropoulos, Afroditi Paveli and Magda Nikolaraizi (University of Thessaly, Greece) investigates the 
impact that different aural renderings have on the comprehension of blind individuals. Their research compares the effective or active listening of participants with blindness when they use digital talking scripts through synthetic speech and DAISY standard. The participants applied more complex navigational routes and their responses towards comprehension questions were more likely correct when the scripts were rendered through DAISY technology rather than through screen reader software.

The following article: "Knowledge tracing with an intelligent agent, in an e-learning platform" describes a study undertaken by Amal Trifa, Aroua Hedhili and Wided Lejouad Chaari (National School of Computer Sciences, Tunisia). They point out that E-learning systems have gained a large student community due to the facility of use and the integration of one-to-one service but that personalisation of the learning process is needed to increase student satisfaction and learning efficiency. This paper deals with the intelligent agent 'Mod-Knowledge' responsible for analysing the student interaction to trace the student knowledge state.

"Formation of students' social competence in a virtual educational environment" comes from Marina Viktorovna Sleptsova (Voronezh State Pedagogical University, Russia) who argues that this represents an urgent pedagogical problem. The article presents the development level of students' social competence through introducing certain variables determined on a relative scale into a mathematical model of the educational process. The research carries out a mathematical apparatus that allows calculation of the parameters of the educational process and variables determined on quantitative and relative scales simultaneously.

Next, A.-M. Korhonen (University of Turku and Häme University of Applied Sciences, Finland), S. Ruhalahti (University of Lapland and Häme University of Applied Sciences, Finland) and M. Veermans (University of Turku, Finland) write about Personal Learning Environments. Their article: "The online learning process and scaffolding in student teachers' personal learning environments" shows that these environments enable lifelong learning and make competences visible in education and professional life. Their study was into how to design an online learning process that enables deep learning through Personal Learning Environments based upon a study of a scaffolding process supported by Web 2.0 tools. They made use of the DIANA pedagogical model to design a dialogical, collaborative, and authentic learning process before comparing its activities against the activities of the five-stage model for scaffolding designed for online learning processes.

Omiros Iatrellis (University of Applied Sciences of Thessaly and Hellenic Open University, Greece), Achilles Kameas (Hellenic Open University, Greece) and Panos Fitsilis (University of Applied Sciences of Thessaly, Greece) then present: "A novel integrated approach to the execution of personalized and self-evolving learning pathways". They argue that to increase quality, one of the challenges to be confronted by Higher Educational Institutions is the provision of personalised education services in a wide range of educational settings. In the paper they present an innovative software environment offered to the academic staff and personnel that provides an integrated information technology solution for the dynamic and personalised composition of students' learning pathways during the execution phase.

"Promoting self-paced learning in the elementary classroom with interactive video, an online course platform and tablets" examines whether this can become 
the means for promoting efficient and effective self-paced learning in the classroom. George Palaigeorgiou and Anthea Papadopoulou (from the University of Western Macedonia, Greece) indicate that studies show how interactive educational video can reduce cognitive overload, guide viewers' attention, and trigger reflection. Tablets can help students to increase self-directed learning, take ownership of the learning process, and collaborate with one another. Students in this study were asked to follow a learning path of interactive videos and other learning units in pairs while the teacher played only a supportive role. The study showed that the proposed learning setting could become a promising means of promoting self-paced interactive learning in the classroom.

Following, "Investigating K-12 teachers' use of electronic board in the classroom in the Central South of United States" by Yixin Zhang (McNeese State University, USA) points out that due to the widespread replacement of traditional blackboards in schools, examining classroom teachers' use of electronic boards is important. The study results show that correlation coefficients of presentation, motivation, engagement and assessment are significantly related, but that teacher self-efficacy and attitudes towards electronic board are significant factors in students' motivation and engagement. Elementary teachers tend to feel more comfortable in using electronic boards than middle school teachers.

"cpm.4.CSE/IRT: Compact process model for measuring competences in computer science education based on IRT models" is from Andreas Zendler (University of Education Ludwigsburg, Germany). The article describes this model that allows the efficient development of measuring instruments for computer science education. Cpm.4.CSE/IRT has four sub processes: B1 determine items, B2 test items, B3 analyse items according to Rasch model, and B4 interpret items by criteria. It is modelled in IDEF0, a process modelling language that is standardised and widely used.

Mohammed Amin Almaiah and Omar Abdulwahab Alismaiel (King Faisal University, Saudi Arabia) next write on: "Examination of factors influencing the use of mobile learning system: An empirical study". The study's purpose was to integrate the Technology Acceptance Model (TAM) with the updated DeLone and McLean's model (DL\&ML) to examine whether quality factors (including system quality, information quality, and service quality) and individual beliefs (including perceived usefulness and perceived ease of use) are the antecedents to students' satisfaction and their intention to use, leading to enhancing their actual usage of mobile learning systems. The results showed that quality factors had significant effect on student satisfaction and their intention to use mobile learning. Also, perceived usefulness had significantly strong impacts on intention to use mobile learning, and satisfaction and intention to use both have significant effects on actual use of mobile learning.

The article that follows is from Ramona Lorenz, Manuela Endberg and Wilfried Bos (TU Dortmund University, Germany), who write on: 'Predictors of fostering students' computer and information literacy - analysis based on a representative sample of secondary school teachers in Germany". German schools are obliged to foster students' digital competences, and their paper aims to provide evidence on the relevance of teacher and school-related factors in the fostering of students' Computer and Information Literacy. It is based on the proficiency levels of students' computer and information literacy from the International Computer and Information Literacy Study (ICILS 2013) and a theoretical approach to media education in schools. The results of the structural equation model used indicate teachers' attitudes towards use of ICT in 
instruction, ICT-related collaboration and sufficient ICT equipment at schools are significant predictors in fostering students' computer and information literacy.

The last paper of this issue: "A valid and reliable tool for examining computational thinking skills" by Mustafa Yağc1 (Ahi Evran University, Turkey) describes the development of a scale to measure the computational thinking skills of high school students. Validity and reliability testing of the scale was performed and it was concluded, as a result of the analysis, that the scale was a valid and reliable measurement tool which could be used to measure the computational thinking skills of high school students.

Finally, I will again make mention of the Encyclopedia of Education and Information Technologies that I am editing for Springer. Putting this together is currently in progress, but it is still possible to make a contribution. The encyclopaedia website is: https://meteor.springer.com/project/dashboard. If you are interesting in making a contribution please let me know (Arthur.Tatnall@vu.edu.au) and I will introduce you to the relevant Section Editor for consideration of your topic.

\section{Arthur Tatnall}

Editor-in-Chief 